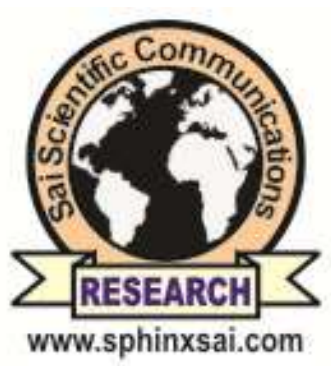

Plitarintegh

International Journal of PharmTech Research

CODEN (USA): IJPRIF, ISSN: 0974-4304, ISSN(Online): 2455-9563

Vol.11, No.04, pp 320-328,

2018

\title{
Tissue Distribution, Cytotoxicity and Pharmacokinetic Studies of Multifunctional Citric Acid Dendrimers using the Drug Cyclophosphamide
}

\author{
B. Narasimha Rao ${ }^{1 *}$, K. Ravindrareddy ${ }^{2}$, K.B.Chandra Sekhar ${ }^{3}$ \\ ${ }^{1 *}{ }^{2}$ Dept. of Pharmaceutics, P Rami Reddy Memorial College of Pharmacy, \\ Kadapa-516003, A.P., India \\ ${ }^{3}$ Director, Oil Technological Research Institute, JNTUA, \\ Anantapuramu-515002, A.P., India
}

\begin{abstract}
The aim of present work is to develop a multifunctional dendritic carrier for targeting tumor cells that overcome drug leakage during circulation and encapsulate tightly an anticancer drug within it through high affinity interactions. PEGylation, polyethylene glycol addition to dendritic carriers improves its circulation time in the body and also ensures high stability without detectable drug release from formulations other than the target site. PEGylated citric acid dendrimer was found an efficient carrier for targeting antitumor agent, cyclophosphamide to the target tumor organs. Dendrimers are repeatedly branched, spherical molecular moieties synthesized by Divergent technique and characterized for acute cytotoxicity assays, pharmacokinetic parameters and tissue distribution studies. Results of the above studies met the objective and tumor uptake of cyclophosphamide has increased significantly when compared with other organs and exhibited relatively lower toxicity to other organs targeting specifically tumor cells. Thus, the data suggest PEGylated citric acid dendrimer-drug complex is a simple and efficient carrier system to deliver drugs to the tumor cells.
\end{abstract}

Key words : Dendrimer, Acute toxicity, Tumor, myeloid, melanoma, multi-functional.

\section{Introduction:}

Melanoma and Leukemia are considered the leading causes of cancer deaths world-wide ${ }^{1}$. Melanoma, a skin cancer, increasing at a rate faster than any other cancers whereas myeloid leukemia, neoplastic proliferation of myeloid cells represents the maximum number of deaths ${ }^{2}$. Chemotherapy of the above cancers is associated with several other undesirable and unwanted side-effects. Therefore, there is a need to control the incidence of these cancers either by early detection or by employing proven prevention methods and techniques ${ }^{3}$. Many studies proved that nanotechnology creates a new pathway for some nano drug delivery systems that reduce the unwanted or undesirable side-effects produced during chemotherapy. In addition, it enhances the efficacy of the drug at the target site ${ }^{4}$. An ideal nanotechnology based tumor therapeutics should be a multifunctional complex device but small enough to leave the vasculature for its specific interaction with the cancer cells followed by their elimination from the body ${ }^{5}$.

B. Narasimha Rao et al /International Journal of PharmTech Research, 2018,11(4): 320-328.

DOI: http://dx.doi.org/10.20902/IJPTR.2018.11404 
Citric acid dendrimers are repeatedly branched polymeric molecules with multiple functional end groups at its terminal surface that provide accessibility to encapsulate a variety of substances such as therapeutic agents, imaging agents, contrasting agents, targeting moieties etc $^{6}$. Drugs either get encapsulated into the interior or conjugated to the surface of dendrimers ${ }^{7}$. Drug retention and their subsequent release from the host dendrimers is strongly affected by the strength of the drug-dendrimer interaction and the water solubility of dendrimers ${ }^{8}$. Properties such as well-defined structure with a monodispersed molecular weight makes them suitable for targeting molecular entities precisely to the cancer tissues through EPR effect ${ }^{9}$. Being water-soluble, citric acid dendrimers prolong the half-life of encapsulated drugs. They take advantage of EPR effect which is commonly observed with tumor cells. Blood vessels of tumors are poorly aligned and possess proliferations in its structure ${ }^{10}$. Owing to this property of tumor cells, nano sized dendrimers easily pass into them without disturbing other healthy cells. Because of poor lymphatic drainage, dendrimers accumulate in tumor cells for a longer time to release the encapsulated drug into them, which simultaneously exhibits therapeutic activity and stand responsible for its destruction ${ }^{11}$.

Cyclophosphamide, a nitrogen-mustard (alkylating agent) is effective against both leukemia and melanoma. CYC is considered among the most potent immunosuppressive drugs today. When administered into body, inactive CYC gets converted to active phosphoramide and acrolein compounds. Formed phosphoramide mustard forms DNA cross-linkage and interferes with the DNA replication. So that the cross-linked tumor cell cannot undergo normal cell division, causing the tumors cells to die ${ }^{12,13,14}$.

\section{Materials and Methods}

Materials : Citric acid dendrimers- G5, Cyclophosphamide was purchased from Yarrow Chemicals, Mumbai; Polyethylene glycol 400 and chloroform were purchased from Finar Chemicals Pvt. Ltd., Ahmedabad; Acetonitrile and N, N'- Dicyclohexylcarbodiimide were bought from Sd Fine Chemicals Ltd., Mumbai. All the chemicals used were of good analytical grade.

Animals : B16F10 animals were procured from NIN, Hyderabad for their use in pharmacokinetic and biodistribution studies. All the animals were inbred for experimental purposes in accordance with CPCSEA guidelines. Animals were housed in individually ventilaged cage system with a $12 \mathrm{hr}$ light/dark cycle. Noise, temperature and humidity were controlled as per the guidelines. They were supplied with standard rodent chow, water and bedding material before surgery. Statement of human and animal rights: This article contains studies with animal subjects performed by authors. Studies were performed after receiving approval from IAEC/CPCSEA. All institutional and national guidelines for the care and use of laboratory were followed. (IAEC/CPCSEA approval no.DL/IAEC/08/16/13).

Cell lines : B16F10 melanoma and K562 myeloid cell lines were procured from ATCC and cultured in DMEM supplemented with $10 \%$ FCS.

Method : Citric acid dendrimers were prepared, PEGylated followed by drug loading in the synthesized citric acid dendrimers.

Synthesis and PEGylation of citric acid dendrimers : $5^{\text {th }}$ generation citric acid dendrimers were synthesized via the same divergent technique as reported in our previous work ${ }^{15}$. The synthesized dendrimers were PEGylated as per the following procedure: Synthesized dendrimers were dissolved in $10 \mathrm{ml}$ of DMF completely and 5 moles of N, N' dicyclohexylcarbodimide was added and stirred thoroughly and kept aside undisturbed for 4 days. After 4 days, reaction mixture was esterified by adding $85 \mathrm{ml}$ of PEG and $150 \mathrm{ml}$ of chloroform to yield a clear solution. Resultant mixture was filtered through separating funnel by adding $5 \mathrm{ml}$ of water that removes completely the unreacted N, N'- dicyclo hexyl carbodimide ${ }^{16}$.

Drug loading in the PEGylated dendrimers : Drug cyclophosphamide was dissolved in distilled water and added to the dendrimer solution dropwise and stirred for around $24 \mathrm{hrs}$ on a magnetic stirrer to ensure complete encapsulation of drug into dendrimers ${ }^{17}$.

Characterization of PEGylated citric acid dendrimers : Synthesized dendrimers were characterized for the following study parameters; 
MTT cytotoxicity assay : MTT cytotoxicity assay was performed individually on B16F10 melanoma cells and K562 myeloid cells. Tumor cells were seeded in 96-well plates at a density of $4.5 \times 10^{3}$ cells/well separately. Synthesized dendrimers were dissolved in DMSO and added to the above wells. Final concentration of citric acid dendrimers in wells was adjusted to get a concentration range of 0.001 to $10 \mu \mathrm{g} / \mathrm{ml}$. Wells were incubated for $96 \mathrm{hrs}$ at $37^{\circ} \mathrm{c}$ with $5 \% \mathrm{CO}_{2}$ and the media was discarded. $100 \mu 1$ of MTT solution was added to each well and incubated for $4 \mathrm{hrs}$. Blue colored formazon crystals formed by proliferating the cells were dissolved in DMSO under safety cabinet. Well plates were placed on a orbital shaker for 10 minutes at room temperature and absorbance of it was measured at $550 \mathrm{~nm}$ by a microplate reader ${ }^{18,19}$.

Tissue distribution studies : Cell lines i.e., B16F10 were injected subcutaneously in balb/c mice respectively to form tumors. Animals were sacrificed and the tumors were propagated in adequate number of experimental animals. Animals bearing a tumor of $100 \mathrm{~mm}^{3}$ were starved overnight and dendrimer formulation containing $10 \mathrm{mg} / \mathrm{ml}$ of drug-dendrimer formulation and drug were injected i.v. through tail vein. Animals were sacrificed at 10, 30, 60, 120 and 180 minutes after injection. Developed tumors and other organs like spleen, liver, kidney and lungs were isolated, washed with distilled water, weighed and homogenized in PBS to $1 \mathrm{~g} / \mathrm{ml}$ of tissue homogenate. Obtained homogenates were centrifuged at 1000rpm and the supernatants were analyzed in HPLC $^{20}$.

Pharmacokinetic studies : All animal procedures were carried as per the protocol approved by CPCSEA on the experimenting animals. Pharmacokinetic studies were performed on B16F10 mice and they have been chosen as model animals for many pharmacokinetic and bioavailability studies. Animals under study were starved overnight. Control group was fed with saline and test group was given dendrimer drug formulation orally. Water was supplied throughout the course of experiment. Blood samples were withdrawn at fixed time intervals such as $0,15,30,60,120$ and 180 minutes respectively. Collected samples were centrifuged at 20000rpm for 10 minutes. Supernatant plasma layer was collected into another tube for HPLC analysis and graphs were plotted against time ${ }^{20}$.

\section{Results and Discussion}

MTT assay : Invitro acute cytotoxicity activity was performed against B16F10 and K562 cell lines by MTT assay. Concentration of the drug i.e., cyclophosphamide in the drug-dendrimer formulations ranged from 0.001 to $10 \mu \mathrm{g} / \mathrm{ml}$. At $0.001 \mu \mathrm{g} / \mathrm{ml}$, cellular proliferation inhibition was $10.47 \%$ whereas at $10 \mu \mathrm{g} / \mathrm{ml}$ percentage inhibition was $62.49 \%$. The cytotoxicity was thought to be a result of interaction between dendrimers and cell surfaces. In addition, there are several studies that prove higher generation dendrimers possess strong cytotoxicity when compared to other lower generations.

Table 1.Tabular representation of MTT assay results against B16F10 cells

\begin{tabular}{|l|l|l|l|}
\hline $\begin{array}{l}\text { Concentration } \\
(\boldsymbol{\mu g} / \mathbf{m l})\end{array}$ & DC & G5DDC & G5D \\
\hline 10 & 74.8 & 62.49 & 10.58 \\
\hline 1 & 43.21 & 34.58 & 11.64 \\
\hline 0.1 & 34.18 & 29.65 & 2.39 \\
\hline 0.01 & 14.78 & 11.24 & 1.28 \\
\hline 0.001 & 10.42 & 10.47 & 2.17 \\
\hline IC50value & $\mathbf{2}$ & $\mathbf{2}$ & $\mathbf{> 1 0 0}$ \\
\hline
\end{tabular}


DC

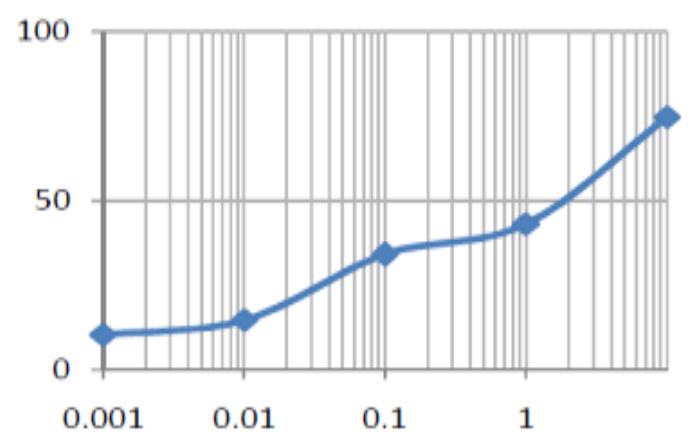

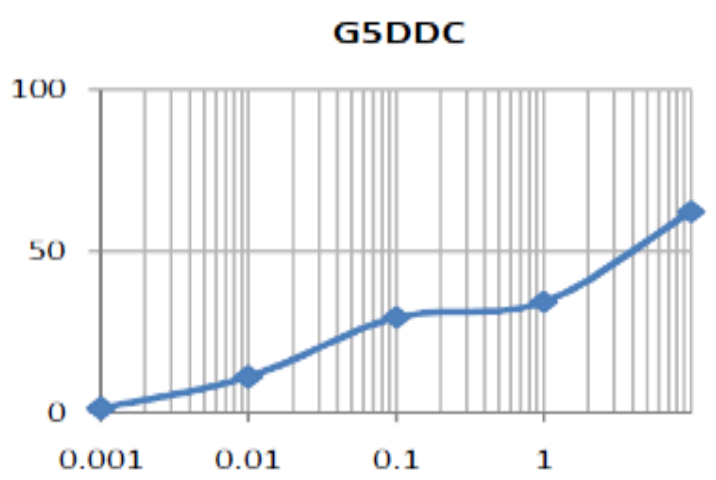

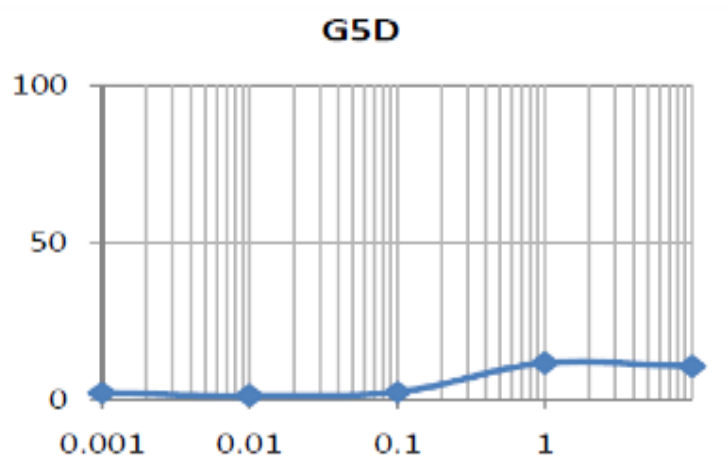

Fig no. 1Graphical representation of MTT assay results for drug Cyclophosphamide for B16F10 cells

Table 2.Tabular representation of MTT assay results against $\mathrm{K562}$ cells

\begin{tabular}{|l|l|l|l|}
\hline $\begin{array}{l}\text { Concentration } \\
(\boldsymbol{\mu} \mathbf{g} / \mathbf{m l})\end{array}$ & DC & G5DDC & G5D \\
\hline 10 & 65.31 & 65.38 & 8.85 \\
\hline 1 & 58.47 & 32.38 & 7.44 \\
\hline 0.1 & 22.48 & 22.95 & 5.21 \\
\hline 0.01 & 12.84 & 3.54 & 6.47 \\
\hline 0.001 & 3.54 & 1.47 & 3.87 \\
\hline IC50value & 0.5 & 4 & $>100$ \\
\hline
\end{tabular}

DC

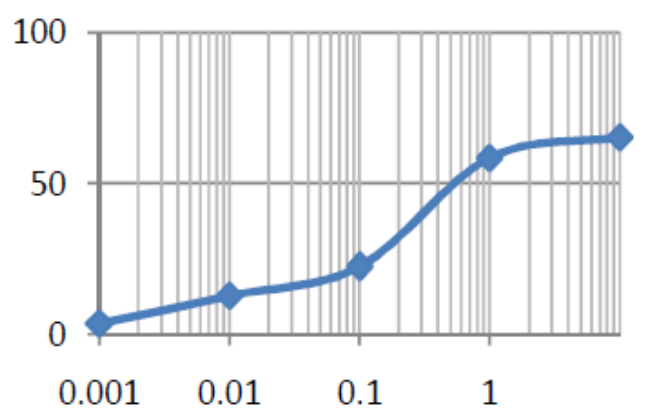

G5DDC

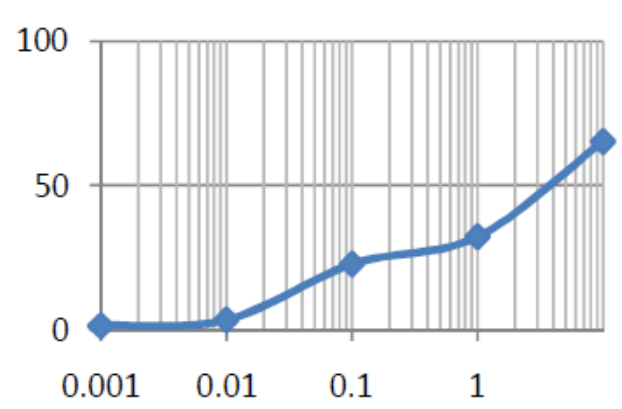




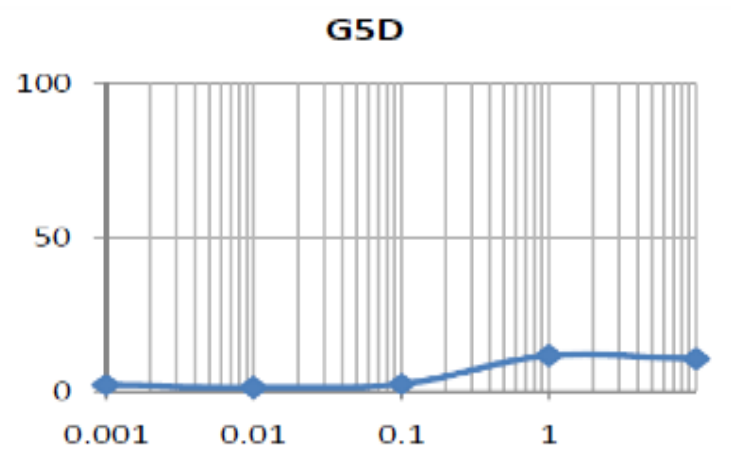

Fig no. 2Graphical representation of MTT assay results for drug Cyclophosphamide for K562 cells

Tissue distribution studies :

Tissue distribution study was performed on B16F10 mice. After administering drug, mice were sacrificed to study drug distribution pattern to various body organs such as tumor, liver, spleen, kidney,lungs. Results demonstrated that tumor uptake of cyclophosphamide-dendrimer formulation increased when compared to other organs. The reason behind the increased uptake of drug-dendrimer formulations by tumor is the enhanced permeation and retention effect. Results of the study are presented below.

Table 3. Tabular representation of tissue distribution study data in tumor $(\mu \mathrm{g} / \mathrm{ml})$

\begin{tabular}{|l|l|l|l|l|l|}
\hline $\begin{array}{l}\text { Distribution } \\
\text { time (min) }\end{array}$ & $\mathbf{1 0}$ & $\mathbf{3 0}$ & $\mathbf{6 0}$ & $\mathbf{1 2 0}$ & $\mathbf{1 8 0}$ \\
\hline DC & 4.86 & 10.06 & 13.5 & 12.5 & 12.52 \\
\hline G5DDC & 5.33 & 9.95 & 18.02 & 16.7 & 17.2 \\
\hline G5D & 0 & 0 & 0 & 0 & 0 \\
\hline
\end{tabular}

Table 4.Tabular representation of tissue distribution study data in lungs ( $\mu \mathrm{g} / \mathrm{ml})$

\begin{tabular}{|l|l|l|l|l|l|}
\hline $\begin{array}{l}\text { Distribution } \\
\text { time (min) }\end{array}$ & $\mathbf{1 0}$ & $\mathbf{3 0}$ & $\mathbf{6 0}$ & $\mathbf{1 2 0}$ & $\mathbf{1 8 0}$ \\
\hline DC & 5.27 & 7.76 & 12.36 & 13.58 & 11.75 \\
\hline G5DDC & 5.33 & 8.82 & 15.3 & 15.10 & 15.0 \\
\hline G5D & 0 & 0 & 0 & 0 & 0 \\
\hline
\end{tabular}

Table 5.Tabular representation of tissue distribution study data in liver $(\mu \mathrm{g} / \mathrm{ml})$

\begin{tabular}{|l|l|l|l|l|l|}
\hline $\begin{array}{l}\text { Distribution } \\
\text { time (min) }\end{array}$ & $\mathbf{1 0}$ & $\mathbf{3 0}$ & $\mathbf{6 0}$ & $\mathbf{1 2 0}$ & $\mathbf{1 8 0}$ \\
\hline DC & 5.65 & 9.61 & 13.22 & 14.30 & 13.21 \\
\hline G5DDC & 6.82 & 7.75 & 16.19 & 16.81 & 16.22 \\
\hline G5D & 0 & 0 & 0 & 0 & 0 \\
\hline
\end{tabular}

Table 6. Tabular representation of tissue distribution study data in kidney $(\mu \mathrm{g} / \mathrm{ml})$

\begin{tabular}{|l|l|l|l|l|l|}
\hline $\begin{array}{l}\text { Distribution } \\
\text { time (min) }\end{array}$ & $\mathbf{1 0}$ & $\mathbf{3 0}$ & $\mathbf{6 0}$ & $\mathbf{1 2 0}$ & $\mathbf{1 8 0}$ \\
\hline DC & 5.59 & 10.69 & 11.41 & 11.87 & 13.57 \\
\hline G5DDC & 5.97 & 9.61 & 11.77 & 16.41 & 16.75 \\
\hline G5D & 0 & 0 & 0 & 0 & 0 \\
\hline
\end{tabular}


B. Narasimha Rao et al/International Journal of PharmTech Research, 2018,11(4): 320-328.

Table 7.Tabular representation of tissue distribution study data in spleen $(\mu \mathrm{g} / \mathrm{ml})$

\begin{tabular}{|l|l|l|l|l|l|}
\hline $\begin{array}{l}\text { Distribution } \\
\text { time (min) }\end{array}$ & $\mathbf{1 0}$ & $\mathbf{3 0}$ & $\mathbf{6 0}$ & $\mathbf{1 2 0}$ & $\mathbf{1 8 0}$ \\
\hline DC & 5.88 & 9.49 & 13.22 & 14.2 & 12.5 \\
\hline G5DDC & 5.99 & 9.75 & 15.37 & 17.2 & 15.05 \\
\hline G5D & 0 & 0 & 0 & 0 & 0 \\
\hline
\end{tabular}

Table 8. Tabular representation of tissue distribution study data for plasma

\begin{tabular}{|l|l|l|l|l|l|}
\hline $\begin{array}{l}\text { Distribution } \\
\text { time (min) }\end{array}$ & $\mathbf{1 0}$ & $\mathbf{3 0}$ & $\mathbf{6 0}$ & $\mathbf{1 2 0}$ & $\mathbf{1 8 0}$ \\
\hline DC & 20.46 & 15.54 & 9.89 & 6.36 & 4.32 \\
\hline G5DDC & 16.01 & 11.37 & 10.12 & 8.93 & 5.91 \\
\hline G5D & 0 & 0 & 0 & 0 & 0 \\
\hline
\end{tabular}

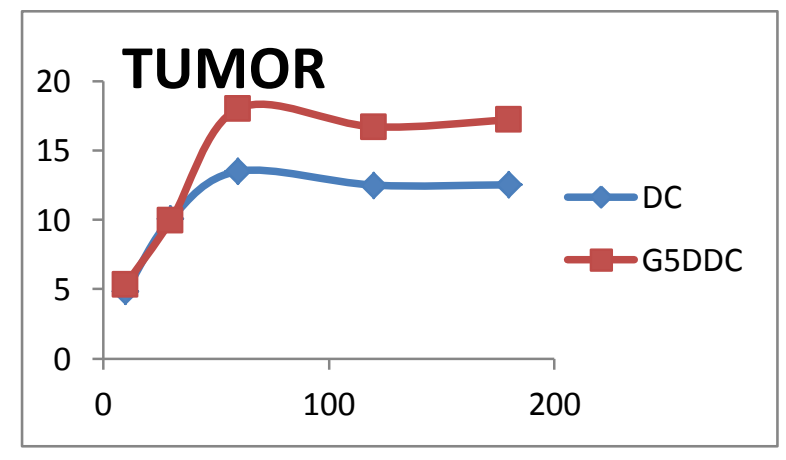

Fig. 3 Graphical representation of tissue distribution study results in Tumor

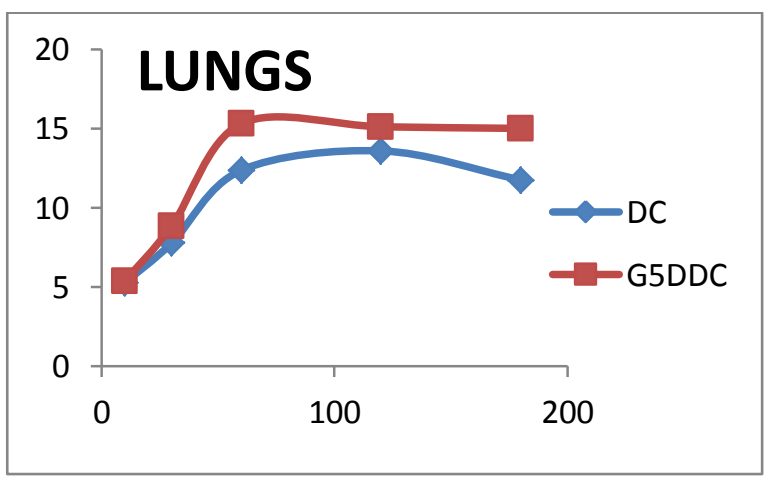

Fig.4 Graphical representation of tissue distribution study results in Lungs

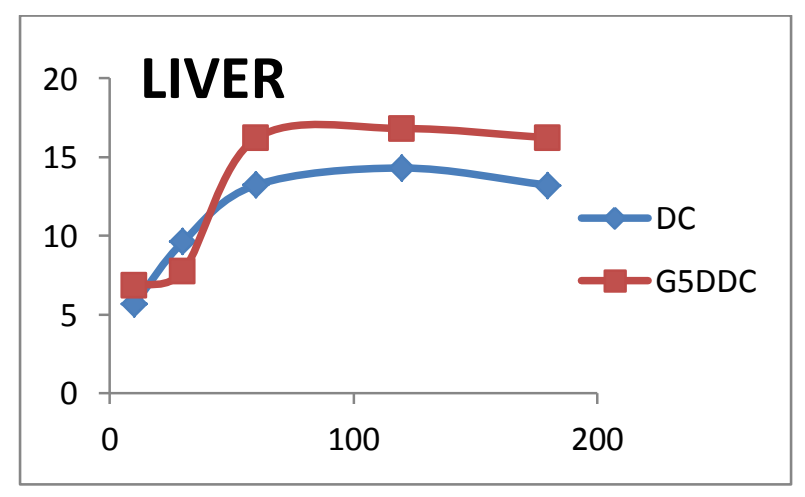

Fig.5 Graphical representation of tissue distribution study results in Liver 


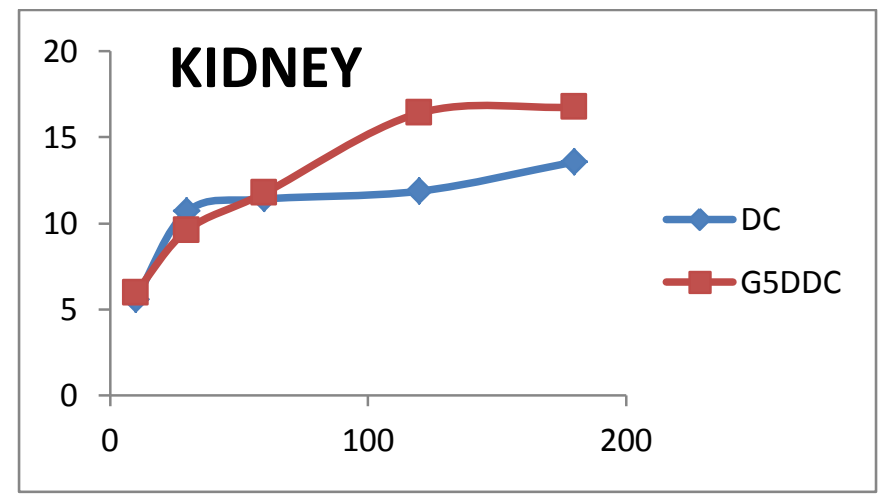

Fig. 6 Graphical representation of tissue distribution study results in kidney

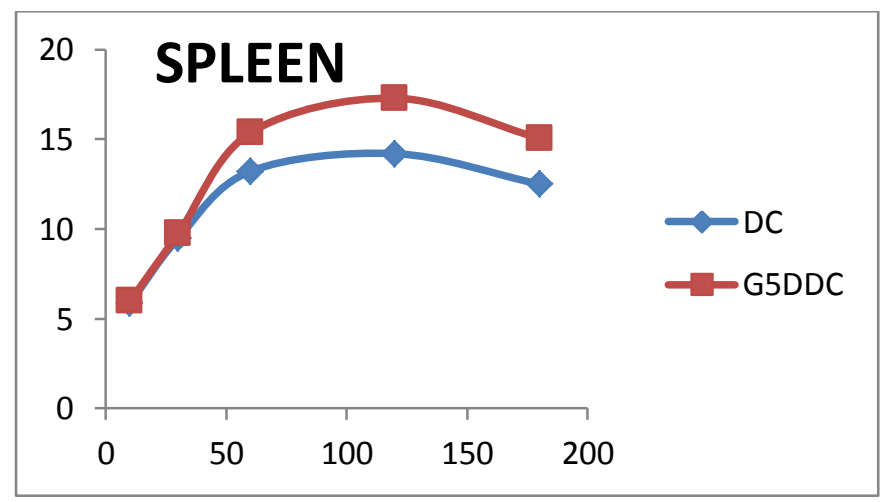

Fig. 7 Graphical representation of tissue distribution study results inSpleen

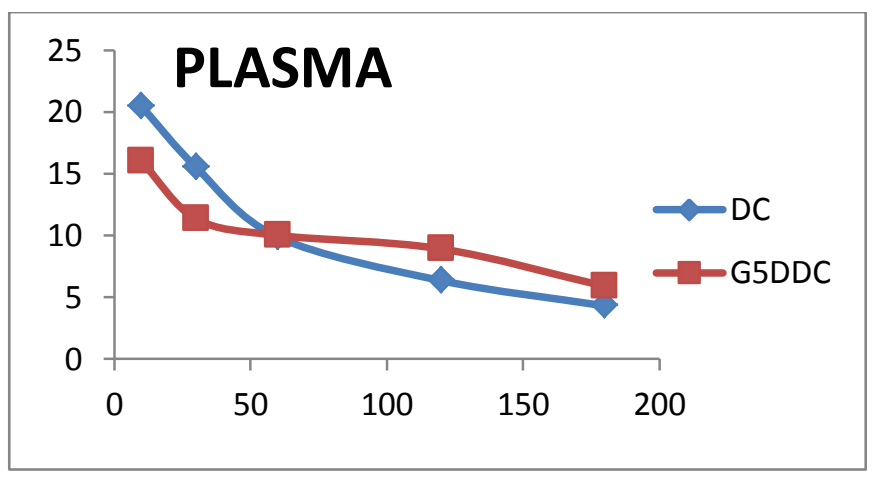

Fig. 8 Graphical representation of tissue distribution study results in plasma

Pharmacokinetic studies :

In-vivo pharmacokinetic studies were performed to quantify the amount of drug from the formulations after the iv administration of drug-dendrimer complex. Fig. 9 shows the mean plasma concentration - time curve of cyclophosphamide after its iv administration. Cmax of drug-dendrimer complex is $16.01 \mu \mathrm{g} / \mathrm{ml}$ and its AUC at the end of 30 minutes is $11.37 \mu \mathrm{g} / \mathrm{ml}$.

Table 9.Pharmacokinetic study parameters

\begin{tabular}{|l|l|l|l|}
\hline Parameters & $\mathbf{C m a x}(\boldsymbol{\mu g} / \mathbf{m l})$ & Tmax $(\mathbf{m i n})$ & $\mathbf{T 1} / \mathbf{2}$ \\
\hline DC & 20.46 & 30 & 110 \\
\hline G5DDC & 16.01 & 30 & 110 \\
\hline
\end{tabular}


Table 10.Plasma AUC

\begin{tabular}{|l|l|l|l|l|l|}
\hline $\begin{array}{l}\text { Distribution } \\
\text { time (min) }\end{array}$ & $\mathbf{1 0}$ & $\mathbf{3 0}$ & $\mathbf{6 0}$ & $\mathbf{1 2 0}$ & $\mathbf{1 8 0}$ \\
\hline DC & 20.46 & 15.54 & 9.89 & 6.36 & 4.32 \\
\hline G5DDC & 16.01 & 11.37 & 10.12 & 8.93 & 5.91 \\
\hline G5D & 0 & 0 & 0 & 0 & 0 \\
\hline
\end{tabular}

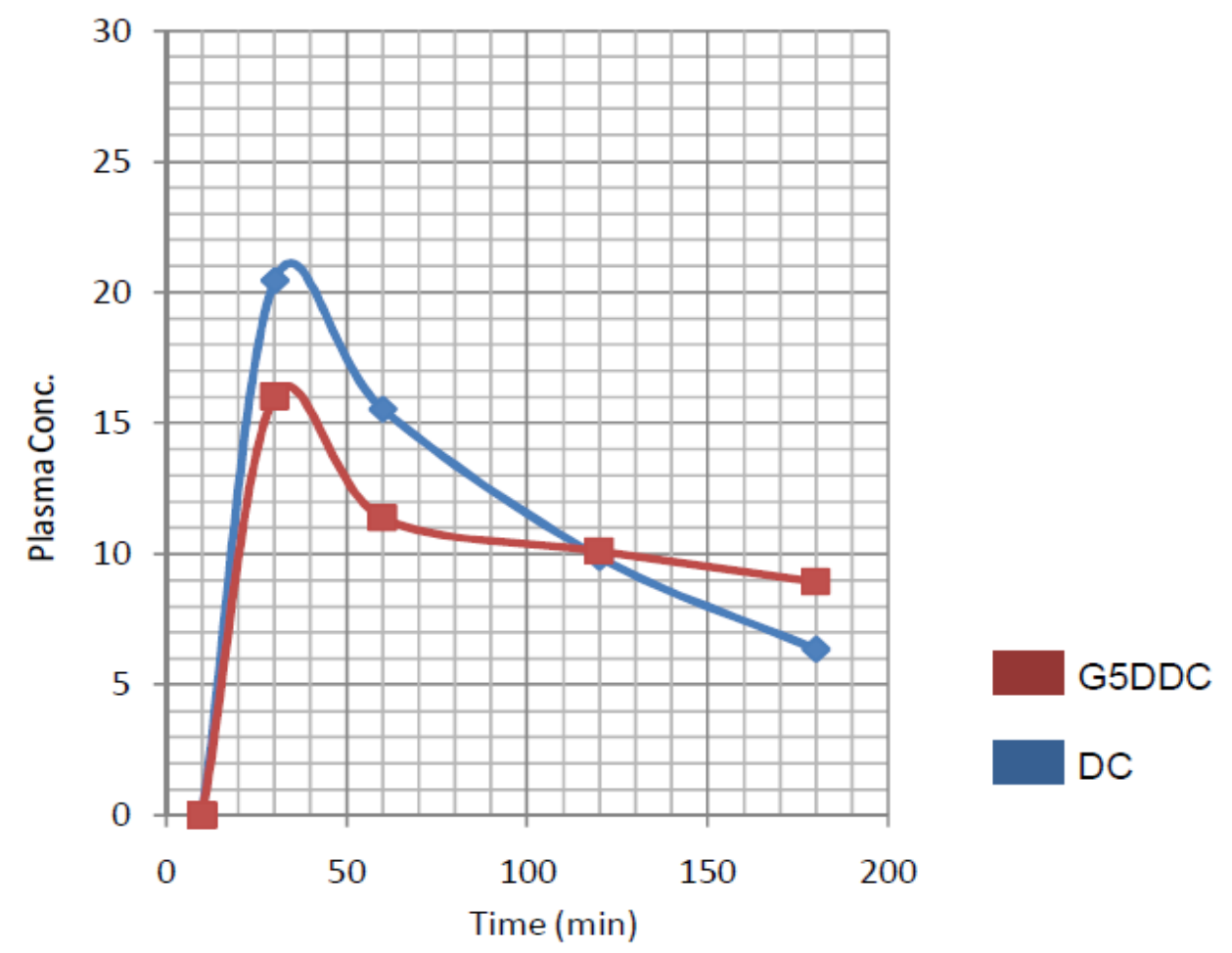

Fig. 9 Graphical representation representing plasma drug concentration

Highly branched citric acid dendrimer was found an effective carrier for encapsulating the hydrophobic moiety, cyclophosphamide. Distribution of drug through drug-dendrimer complex in the mouse body was timedependent manner against B16F10 cells. When compared to other organs, cyclophosphamide uptake increased significantly in tumor cells and higher generation dendrimer exhibited strong cytotixic activity when compared to other lower generations.

\section{Acknowledgement}

Above research work did not receive any funding from any kind of funding sources.

\section{Funding}

NIL

\section{Conflict of Interest}

All authors (B. NarasimhaRao, K. Ravindra Reddy, K. B. Chandra Sekhar) declare that they have no conflict of interest. 


\section{References}

1. Jemal, A., Bray, F., Center, M. M., Ferlay, J., Ward, E., \& Forman, D. (2011). Global cancer statistics. Cancer Journal for Clinicians, 61(2), 69-90. doi:10.3322/caac.20107.

2. Stone, R.M., ODonnell, M.R. and Sekeres, M.A., Acute myeloid leukemia, Hematology. American Society of Hematology. Education Program. 2004, 98-117.

3. Sbeity, H. (2015). Review of Optimization Methods for Cancer Chemotherapy Treatment Planning. Journal of Computer Science and Systems Biology, 8(2), 74-95. doi:10.4172/jcsb.1000173.

4. McMillan, J. E., Batrakova, E., \& Gendelman, H. E. (2011). Cell Delivery of Therapeutic Nanoparticles. Progress in Molecular Biology and Translational Science, 104, 563-601. doi:10.1016/B978-0-12416020-0.00014-0.

5. Biswas, A. K., Islam, M. R., Choudhury, Z. S., \& Mostafa, A. (2014). Nanotechnology based approaches in cancer therapeutics. Advances in Natural Sciences: Nanoscience and Nanotechnology., 5, $1-11$.

6. Pandya, D. P., Chaudhari, M. J., Thakkar, P. P., \& Soni, A. M. (2012). Dendrimer: A Novel Polymer. International Journal for Pharmaceutical Research Scholars., 1, 404-420.

7. Lin, Q., Jiang, G., \& Tong, K. (2010). Dendrimers in Drug-Delivery Applications. Designed Monomers and Polymers, 13(4), 301-324. doi:10.1163/138577210X509552.

8. Kumari, A., Singla, R., \& Anika, G. (2014). Nanoencapsulation for drug delivery. EXCLI Journal, 13, 265-286.

9. Abbasi, E., Aval, S. F., Akbarzadeh, A., Milani, M., Nasrabadi, H., Joo, S., . . ., \& Pashaei-Asl, R. (2014). Dendrimers: synthesis, applications, and properties. Nanoscale Research Letters, 9(1), 247. doi:10.1186/1556-276X-9-247.

10. Namazi, H., \& Motamedi, S. (2011). Synthesis of New Functionalized Citric Acid-based Dendrimers as Nanocarrier Agents for Drug Delivery. BioImpacts, 1, 63-69.

11. Peer, D., Karp, J. M., Hong, S., Farokhzad, O. C., Margalit, R., \& Langer, R. (2007). Nanocarriers as an emerging platform for cancer therapy. Nature Nanotechnology, 2(12), 751-760. doi:10.1038/nnano.2007.387.

12. Fenselau, C., \& Kan, M. N. (1977). Identification of aldophosphamide as a metabolite of cyclophosphamide in vitro and in vivo in humans. Cancer Research, 37, 2538-2543.

13. Zon, G., Ludeman, S. M., Brandt, J. A., Boyd, V. L., Ozkan, G., Egan, W., \& Shao, K. L. (1984). NMR spectroscopic studies of intermediary metabolites of Cyclophosphamide. Journal of Medicinal Chemistry, 27(4), 466-485. doi:10.1021/jm00370a008.

14. Shulman-Roskes, E. M., Noe, D. A., Gamcsik, M. P., Marlow, A. L., Hilton, J., Hausheer, F. H., . .., \& Ludeman, S. M. (1998). The partitioning of phosphoramide mustard and its aziridinium ions among alkylation and P-N bond hydrolysis reactions. Journal of Medicinal Chemistry, 41(4), 515-529. doi:10.1021/jm9704659.

15. Rao, B. N., Fathima, S. R., Viswanath, V., Prakash, K. G., Padmini, D. S., \& Reddy, P. S. (2016). Novel Citric Acid Dendritic Hydrogels for the Delivery of Econazole Nitrate and its Antifungal Activity. Journal of Applied Pharmaceutical Science, 6, 94-102. doi:10.7324/JAPS.2016.601213.

16. Reddy, M.S., Tejaswi, Y., Kalyan, A.V., Sravya, R. andNamrath, M., (2014). Novel Drug Delivery of Minocycline aganist Bacteria by using a Polymer Citric Acid macro molecule. Indian Journal of Research in Pharmacy and Biotechnology, 2, 1161-1166.

17. Rao, B. N., Viswanath, V., \& Purushothaman, M. (2015). Synthesis and Formulation of new Functionalized Citric Acid based Dendrimers for Drug Delivery using an Anti Bacterial agent. World Journal of Pharmaceutical Research., 4, 1054-1062.

18. Jiang, Y. Y., Tang, G. T., Zhang, L. H., Kong, S. Y., Zhu, S. J., \& Pei, Y. Y. (2010). PEGylated PAMAM dendrimers as a potential drug delivery carrier: in vitro and in vivocomparative evaluation of covalently conjugated drug and non-covalent drug inclusion complex. Journal of Drug Targeting, 18.

19. Hamidi, A., Sharifi, S., Davaran, S., Ghasemi, S., \& Omidi, Y. (2012). Novel Aldehyde-Terminated Dendrimers; Synthesis and Cytotoxicity Assay. BioImpacts, 2, 97-103.

20. Cui, D., Xu, Q., Gu, S., \& Shi, J. (2009). PAMAM-drug complex for delivering anticancer drug across blood-brain barrier in-vitro and in-vivo. African Journal of Pharmacy and Pharmacology, 3, 227-233. 